\title{
Ein Verfahren zur Injektion fadenförmiger Implantatmaterialien
}

\section{Journal Article}

Author(s):

Lüscher, P.; Wintermantel, E.; Annen, M.

Publication date:

1995

Permanent link:

https://doi.org/10.3929/ethz-b-000422549

Rights / license:

In Copyright - Non-Commercial Use Permitted

Originally published in:

Biomedizinische Technik 40(s1), https://doi.org/10.1515/bmte.1995.40.s1.395 


\section{Ein Verfahren zur Injektion fadenförmiger Implantatmaterialien}

$P$. Lüscher, E. Wintermantel und M. Annen

Professur für Biokompatible Werkstoffe und Bauweisen, ETH Zürich

\section{Einleitung}

Metabolisch induktive Implantate wie ArzneimittelFreisetzungssysteme und tissue scaffolds gewinnen zunehmend an Bedeutung. Minimal invasive Implantationsverfahren versprechen für diese Materialien neben der geringeren Belastung des Patienten eine bessere biologische Reaktion durch die Vermeidung operativ bedingter Schädigungen im umliegenden Gewebe. Implantatformen, welche minimal invasiv implantiert werden können, sind injizierbare microspheres, in situ gelierende Lösungen und stäbchenförmige Implantate, die subcutan eingesetzt werden.

Ein neu entwickeltes Implantationsverfahren ermöglicht die Injektion von fadenförmigen Werkstoffen. Das Verfahren eröffnet neue therapeutische Möglichkeiten für zahlreiche Problemstellungen.

\section{Injektionsverfahren}

Das Implantationsverfahren ist in Abb. 1 schematisch dargestellt. Das fadenförmige Implantatmaterial wird zusammen mit einer Flüssigkeit (Trägerfluid) injiziert und bildet im Gewebe eine offenporige Struktur in der Form eines Fadenknäuels aus. Die Injektion kann durch eine Kanüle, einen Katheter oder durch einen Endoskopkanal, in Weichgewebe oder in Körperhohlräume erfolgen. Eine theoretisch unbegrenzte Menge an Material kann implantiert werden. Die Grösse und die Form des Implantats sind intraoperativ bestimmbar. Die Injektion kann für grössere Implantatvolumina mit einer Flüssigkeitspumpe und Ventilen kontrolliert werden, für andere Anwendungen genügen Einweg-Injektionsvorrichtungen wie in $\mathrm{Abb} .2$ dargestellt.

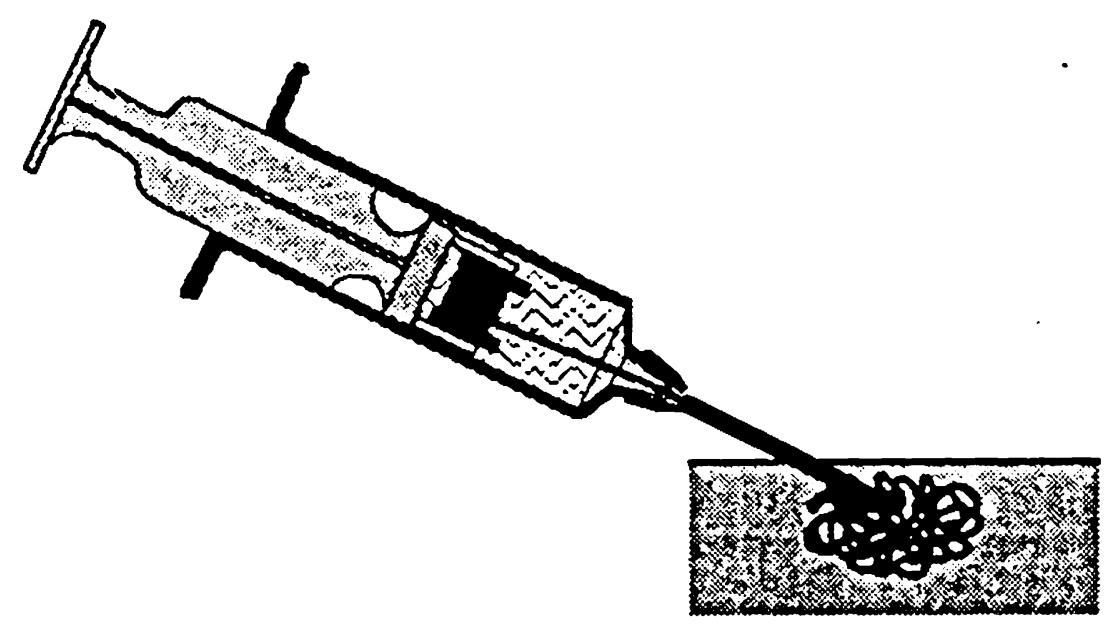

Abb. 2: Injektionsvorrichtung als Einwegsystem. Die Rolle mit dem Implantatwerkstoff ist in eine mit Flüssigkeit gefüllte Spritze integriert.

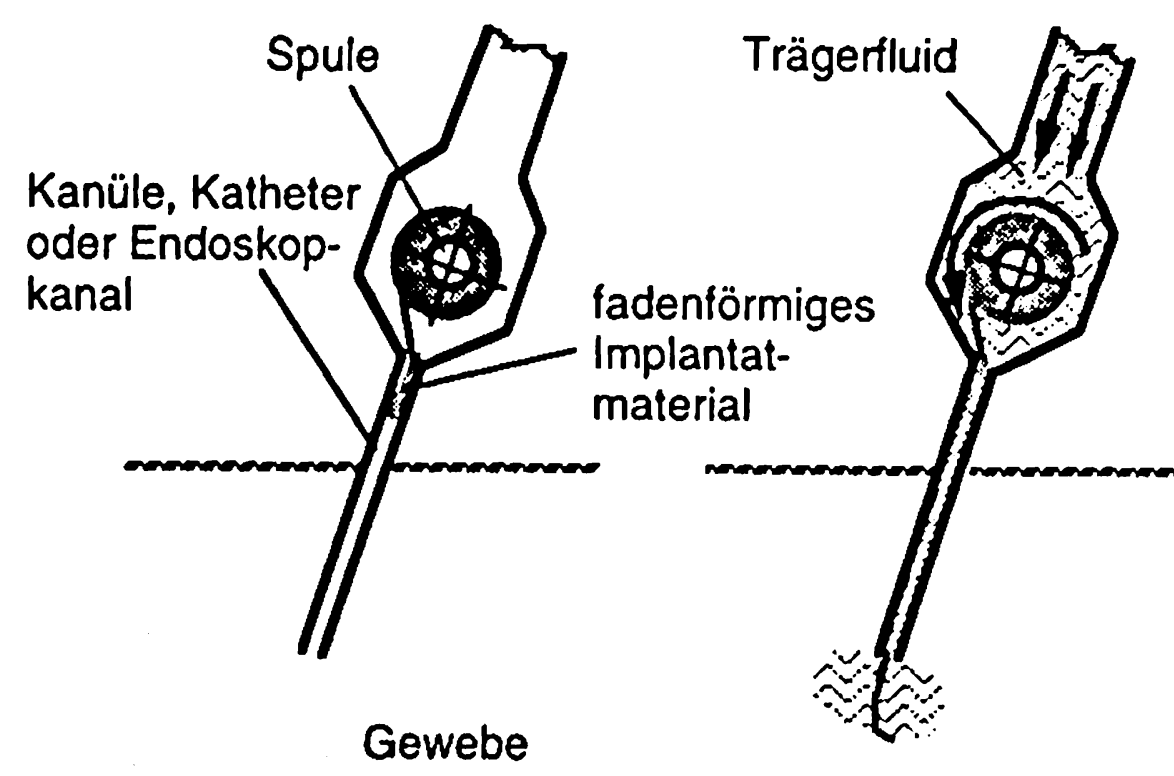

a

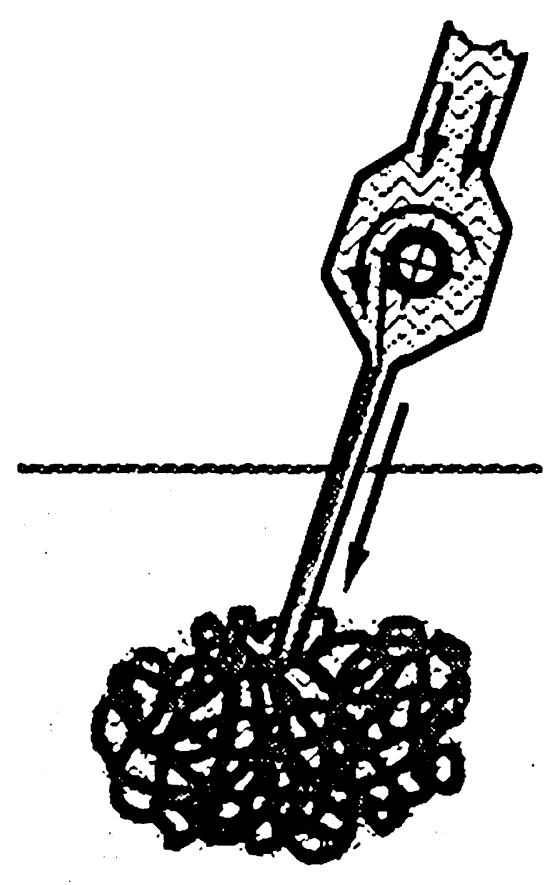

C

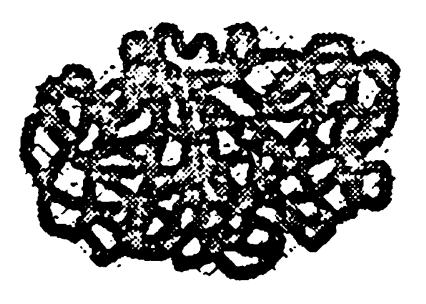

d

Abb. 1, a: Injektionsvorrichtung vor der Implantation. Das Implantatmaterial ist auf einer drehbaren Spule aufgerollt und ein Fadenende ist in den Injektionskanal eingeführt. b: Durch die Injektion einer Flüssigkeit (Trägerfluid) wird der Faden durch den Kanal transportiert und gleichzeitig von der Spule abgewickelt. Das Trägerfluid beginnt im Gewebe einen Hohlraum aufzuspannen. c: Implantatwerkstoff und Trägerfluid werden kontinuierlich in den Hohlraum eingespritzt. Der Werkstoff legt sich dort als offenporige Knäuelstruktur ab. Ein Teil des Trägerfluids kann vor dem Zurückziehen des Injektionskanals wieder abgesaugt werden. d: Das Porenvolumen des injizierten Implantats wird anfänglich vom Trägerfluid ausgefüllt. 


\section{Implantatmaterialien}

Die mechanischen .Eigenschaften des Fadens begrenzen die Auswahl der Implantatwerkstoffe. Der kritischer Wert ist die Biegesteifigkeit. Sie muss genügend klein sein, damit sich das Material als Knäuelstruktur am Implantationsort ablegen kann (Abb. 3, 4). Die Biegesteifigkeit der verwendeten Fäden konnte mangels geeigneten Messmethoden nicht quantifiziert werden.

Neben Monofilamenten in variablen Durchmessern sind auch Multifilamente und Fäden mit diskontinuierlichen Durchmessern sowie Hohlfasern und oberflächenstrukturierte Fasern injizierbar. Damit können auch aus eher steifen Materialien injizierbare Fäden hergestellt werden. Polymere, Hydrogele, Biopolymere oder Verbundwerkstoffe wie Polymer-KeramikKomposite können eingesetzt werden. Zusätzlich sind verschiedene Trägerfluide verwendbar, beispielsweise Ringerlösung, Blut, Gase oder ein biologischer Kleber.

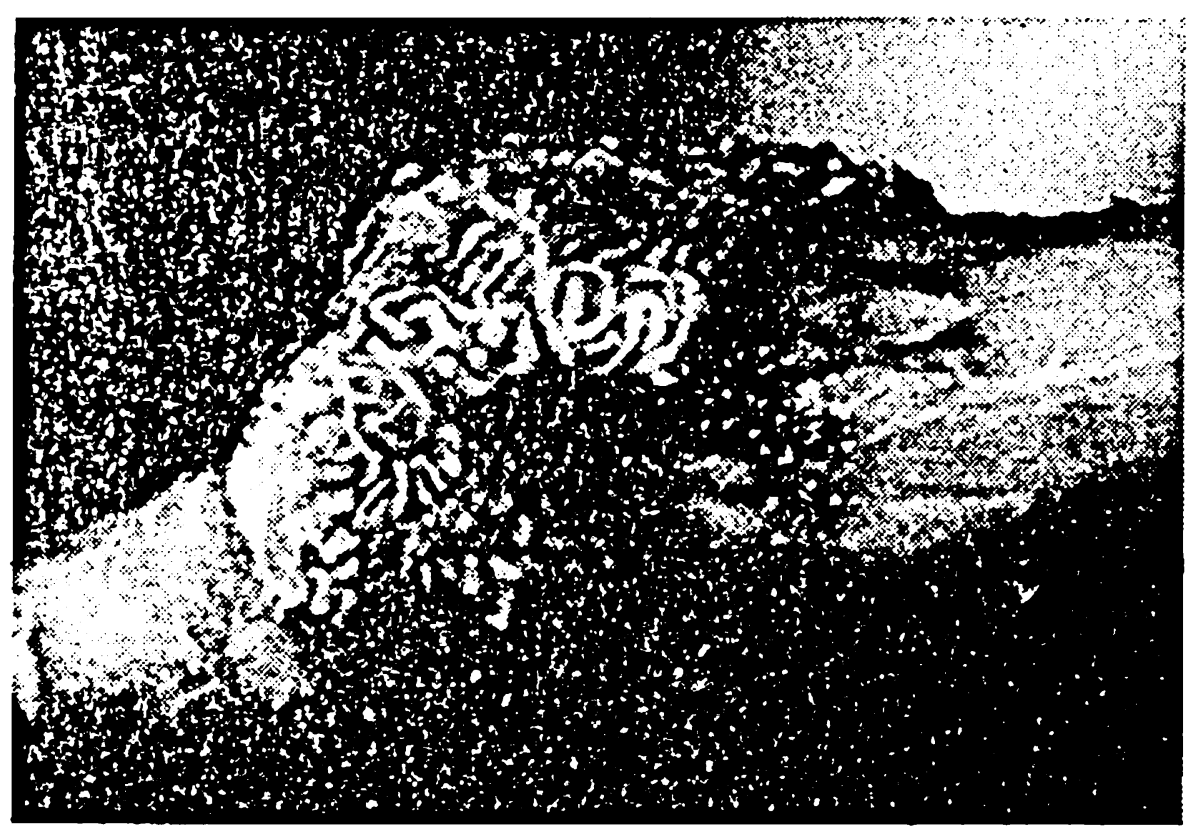

Abb. 3: Ein auf Knochengewebe injizierter Modellfaden aus Calciumalginat (post mortemStudie). Das umliegende Weichgewebe wurde nach der Injektion entfernt. Gut sichtbar ist die offenporige Knäuelstruktur des Implantats.

\section{Potentielle Anwendungen}

Das einfache Funktionsprinizip, die Vielfältigkeit an Implantatwerkstoffen und die Knäuelstruktur als Implantatform eröffnen neue Möglichkeiten in einem breiten Spektrum von Anwendungsgebieten.

Die Injektionstechnik ermöglicht die Verwendung von Fasern und Fäden als injizierbare Implantatform für Arzneimittel-Freisetzungssysteme (2). Zu deren Herstellung können Produktions- und Verarbeitungstechnologien aus der Textilindustrie adaptiert werden. Zusätzlich ist ein Faden kohärent, wodurch die Migration von Partikeln im Gewebe, wie es bei Microspheres-vorkommen kann, verhindert ist. Dies ist vorteilhaft für 'die kontrollierte Freisetzung von lokal wirkenden Substanzen, wie Chemotherapeutika oder Antibiotika.
Die offenporige Implantatstruktur kann für gewebsinduzierende Werkstoffe genutzt werden. Zellen und Blutgefässe können in die Poren einwachsen und dort zur Bildung von neuem Gewebe angeregt werden. Mögliche Anwendungen sind die Behandlung von Knochendefekten und das Tamponieren von Hohlräumen nach Gewebsresektionen in minimal invasiver Technik. Die Geometrie des Implantats kann während der Injektion den lokalen Gegebenheiten angepasst werden.

Eine weitere potentielle Anwendungen ist die therapeutische Embolisation von Tumoren und Hämangiomen, indem ein Fadenknäuel durch dünne Katheter in Blutgefässe appliziert wird. Ferner ist die Injektionstechnik für die Zelltransplantation interessant. In Hydrogelfäden verkapselte Zellen können minimal invasiv implantiert werden und bleiben durch die Kohärenz des Fadens gut lokalisierbar.

Die Injektionstechnik für fadenförmige Werkstoffe stellt damit ein vièseitiges Basisverfahren für zahlreiche neue Therapiemöglichkeiten dar.

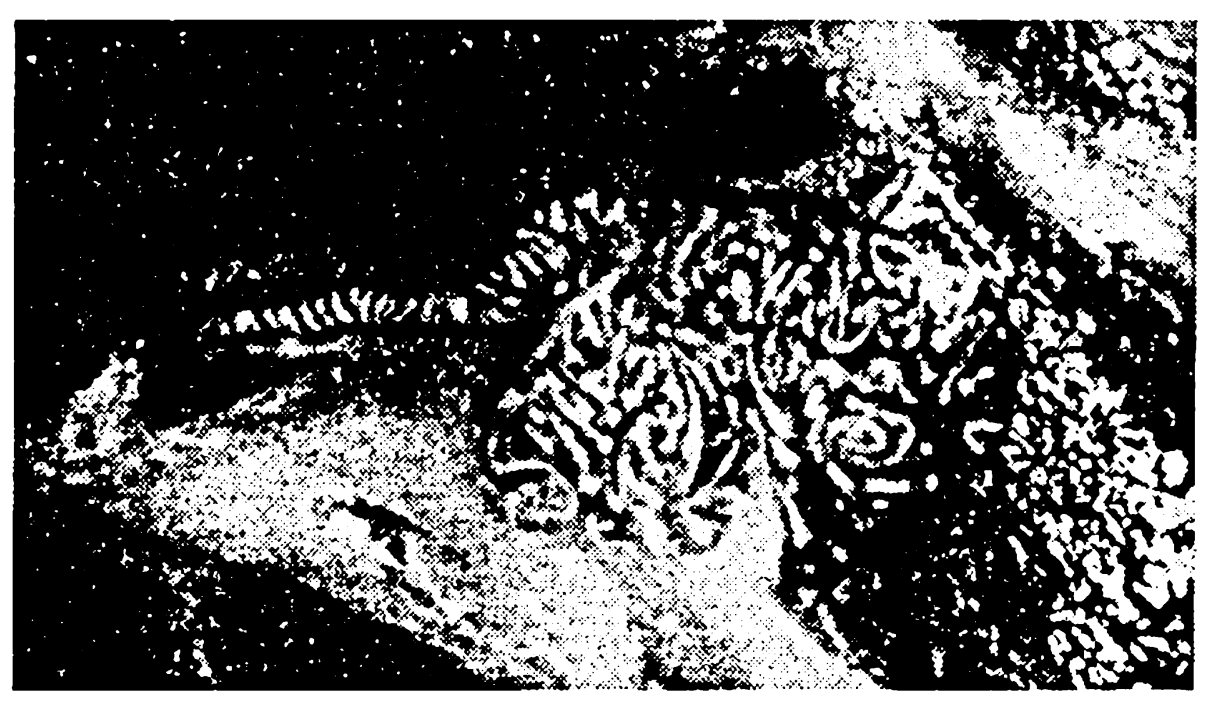

Abb. 4: Ein in Weichgewebe injizierter Faden (Querschnitt durch Implantat und Gewebe, post mortem-Studie). Die Implantatstruktur ist im allgemeinen amorph. Eine geordnete, spiralartige Struktur (links im Bild) wurde bei der Injektion von Faden während dem Zurückziehen des Kanals gebildet.

\section{Literatur}

(1) Schweizer Patent Nr. 2533/94-3 (1994)

(2) Lüscher, P., Wintermantel, E. und Annen, M.: A New Injectable Implant System for Drug Delivery. 14th Pharmaceutical Technology Conference, vol. 2, 55-61 (1995)

Dieses Projekt wurde vom Schwerpunktprogramm Werkstofforschung (WF-START) unterstützt (Pojekt Nr. 4.B.1). 